\title{
KEPADATAN POPULASI TUNGAU DEBU RUMAH PADA KAMAR TIDUR PONDOK PESANTREN X DI KOTA BEKASI
}

\author{
Reza Anindita ${ }^{1,}$ Renita Yuana Putri ${ }^{2}$ \\ 1. Program Studi S1 Farmasi, STIKes Mitra keluarga, Depok-Indonesia \\ 2. Program Studi DIII TLM, STIKes Mitra keluarga, Depok-Indonesia
}

*Korespondensi: Reza Anindita | STIKes Mitra Keluarga | rezaaninditaa@ gmail.com

\begin{abstract}
Abstrak
Pendahuluan: Tungau debu rumah (TDR) merupakan sumber alergen yang berpotensi menyebabkan alergi pada manusia. Komponen tubuh TDR yang berpotensi menyebabkan alergi pada manusia antara lain kutikula, organ reproduksi, saluran pencernaan dan feses. Adapun persentase TDR yang berpotensi menyebabkan alergi di Asia sebesar $60 \%$. Mengingat dampak buruk TDR bagi kesehatan khususnya di Indonesia, maka perlu dilakukan penelitian mengenai identifikasi dan kepadatan populasi TDR pada salah satu pondok pesantren di kota bekasi. Tujuan Penelitian untuk memberikan informasi mengenai kepadatan populasi TDR pada tempat tidur pondok pesantren di Kota Bekasi.

Metode: Jenis penelitian ini adalah deskriptif dengan desain penelitian cross sectional menggunakan teknik sampling total sampling.

Hasil: Identifikasi TDR pada sampel tempat tidur pada pondok pesantren X di Kota Bekasi hanya menunjukkan genus Dermatophagoides sp. dengan rata-rata kepadatan tertinggi sebesar 13,80 tungau/gram debu sedangkan terendah sebesar 4,50 tungau/gram debu.

Kesimpulan: Dari semua sampel debu kamar tidur di pondok pesantren $\mathrm{X}$ kota Bekasi hanya ditemukan genus Dermatophagoides sp dengan kepadatan tertinggi sebesar 13,80 tungau/gram debu.
\end{abstract}

Kata Kunci: TDR, Dermatophagoides sp, Alergi.

Diterima 13 Mei 2021; Accepted 30 Juni 2021

\section{PENDAHULUAN}

Tungau Debu Rumah (TDR) merupakan salah satu sumber alergen yang berpotensi memicu terjadinya reaksi alergi pada manusia. Beberapa komponen tubuh TDR yang berpotensi sebagai sumber alergen adalah Kutikula, organ reproduksi, saluran pencernaan dan feses. Semua komponen TDR dapat masuk ke dalam tubuh manusia dan memicu reaksi alergi melalui inhalasi dan penetrasi kulit (Widiastawan, Wahongan and Bernadus, 2015).

Yu et al (2015) melaporkan bahwa rata-rata persentase TDR sebagai penyebab alergen pada manusia di seluruh dunia sebesar $50 \%$. Mondal et al (2019) menambahkan bahwa persentase TDR dalam menyebabkan alergi di Asia sebesar $60 \%$, Eropa sebesar 21,7 \% dan USA sebesar $20 \%$. Adapun genus TDR yang berpotensi memicu reaksi alergi adalah Dermatophagoides dengan spesies dominan Dermatophagoides pteronyssinus dan Dermatophagoides farinae.

Mengingat dampak buruk yang disebabkan oleh TDR bagi kesehatan manusia, seperti asma, rhinitis alergi dan dermatitis atopic, khususnya di Indonesia maka perlu dilakukan penelitian awal mengenai identifikasi dan gambaran kepadatan populasi TDR di suatu daerah. Informasi mengenai kepadatan populasi TDR akan menjadi acuan database dalam melakukan upaya pencegahan dan pengobatan di daerah tersebut.

Adapun penelitian mengenai identifikasi dan gambaran TDR pernah dilakukan di Indonesia, seperti pada penelitian Kawulur et al (2013) di Kelurahan Teling Bawah Kecamatan Wenang Kota Manado yang melaporkan bahwa genus TDR yang dominan ditemukan adalah Dermatophagoides spp dengan kepadatan tertinggi di kamar tidur. Kesimpulan yang sama juga diperoleh Widiastawan et al (2015) yang menyebutkan bahwa Dermatophagoides sp. merupakan genus paling dominan yang ditemukan pada sampel debu rumah. Adapun kepadatan TDR secara keseluruhan dominan ditemukan pada sampel debu yang diambil dari kamar tidur.

Penelitian lain mengenai TDR pada penderita alergi juga pernah dilakukan Nova et al (2018) pada penderita alergi rhinitis di panti asuhan Koto Tengah Padang yang melaporkan bahwa dari 81 tungau yang ditemukan sebanyak 34,6 \% merupakan genus Dermathopagoides sp. dengan kepadatan TDR pada 
penderita alergi rhintis sebanyak 6,29 tungau dan non alergi rhinitis sebanyak 6,33 tungau. Penelitian lain dilakukan oleh Lesmana et al (2019) yang menyebutkan bahwa identifikasi 30 rumah pasien dermatitis atopik yang berobat di RSUD Petala Bumi Pekanbaru menunjukkan $100 \%$ teridentifikasi positif adanya TDR dengan lokasi dominan ditemukan TDR adalah kamar tidur. Selanjutnya Arrahmi et al (2019) melaporkan bahwa spesies TDR yang dominan ditemukan pada sampel debu rumah di Kelurahan Jati Kecamatan Padang Timur Kota Padang adalah Dermatophagoides pteronyssinus, sedangkan yang paling sedikit ditemukan adalah Dermatophagoides farinae dengan kepadatan TDR tertinggi untuk Dermatophagoides pteronyssinus ditemukan pada kasur dan sprei. Selanjutnya Rahmadatu dan Sulistyaningsih (2019) menambahkan bahwa terdapat korelasi antara kepadatan Dermatophagoides spp. dengan frekuensi serangan asma pada penderita asma di RS Paru Jember. Adapun kekuatan korelasi tersebut termasuk kategori sedang.

Penelitan terbaru mengenai TDR dilakukan oleh Setyabudi dan Song (2020). Penelitian tersebut ingin mengetahui gambaran kepadatan TDR pada salah sekolah $\mathrm{X}$ di Jakarta. Hasil penelitian tersebut menunjukkan bahwa dari 90 ruangan, 44 ruang positif terdapat TDR. Adapun dari 290 tungau sebanyak 10 $(3,11 \%)$ ditemukan di SD, 98 (33,91\%) ditemukan SMP dan 182 (62,98\%) ditemukan di SMA.

Berdasarkan lokasi penelitian mengenai identifikasi dan kepadatan TDR yang sudah pernah dilakukan di Indonesia, belum pernah ada penelitian mengenai TDR yang dilakukan di kota Bekasi. Oleh sebab itu peneliti tertarik untuk melakukan penelitian awal mengenai kepadatan TDR di kota Bekasi, khususnya di pondok pesantren dengan pengambilan sampel TDR pada debu kamar tidur.

Adapun tujuan dari penelitian ini adalah memberikan informasi mengenai kepadatan populasi TDR pada tempat tidur pondok pesantren X di Kota Bekasi. Hasil penelitian ini dapat dijadikan salah satu sumber database mengenai keberadaan TDR pada pondok pesantren di kota Bekasi. Adanya database tersebut memainkan peranan penting dalam upaya pengendalian penyebaran TDR sebagai salah satu sumber alergen di kota Bekasi.

\section{METODE}

Jenis penelitian yang digunakan merupakan penelitian deskriptif dengan desain penelitian cross sectional. Teknik pengambilan sampel pada penelitian ini menggunakan total sampling, yaitu pengambilan sampel dengan jumlah sampel sama dengan jumlah populasi. Lokasi pengambilan sampel dilakukan di Pondok Pesantren Bekasi pada tanggal 1 Maret 2020. Pemeriksaan sampel dilakukan di Laboratorium Parasitologi STIKes Mitra Keluarga pada tanggal 4 Maret-9 Maret 2020. Populasi sekaligus sampel dalam penelitian ini adalah debu yang diambil dari 13 tempat tidur pada Pondok Pesantren di kota Bekasi.

\section{Pengumpulan, Identifikasi dan Penghitungan kepadatan TDR}

Alat yang digunakan dalam penelitian ini adalah mikroskop, vacuum cleaner, neraca analitik, tabung reaksi, rak tabung, gelas ukur, gelas kimia, spatula, batang pengaduk, object glass, cover glass, bulb, pipet ukur, pipet tetes, kertas saring, wadah pot plastik, masker, handscoon, label, alat tulis, sedangkan bahan yang digunakan dalam penelitian ini adalah reagen $\mathrm{NaCl} 0,9 \%$ akuades, dan sampel debu yang diperoleh dari kamar tidur di Pondok Pesantren kota Bekasi.

Sampel debu diambil pada tempat tidur responden yang berada di Pondok Pesantren Bekasi. Sampel debu diambil pada seluruh permukaan tempat tidur dengan menggunakan vacuum cleaner. Sampel debu yang diambil pada setiap ruangan yang berbeda, filter pada vacuum cleaner dibersihkan untuk mendapatkan debu yang valid. Sampel yang telah terkumpul kemudian dimasukkan ke dalam wadah pot plastik dan diberi label nomor sampel dan tanggal pengambilan. Sampel debu kemudian dibawa ke Laboratorium Parasitologi STIKes Mitra Keluarga Bekasi untuk dilakukan pemeriksaan. Sampel debu kemudian diletakkan pada kertas saring dan ditimbang dengan menggunakan necara analitik. Sampel debu kemudian diambil sebanyak 0,1 gram, dimasukkan ke dalam tabung reaksi dan di tambahkan larutan $\mathrm{NaCl}$ $0,9 \%$ kemudian di homogenkan. Setelah dihomogenkan kemudian ditambahkan dengan larutan $\mathrm{NaCl}$ jenuh hingga terbentuk konveks pada permukaannya. Bagian permukaan tabung reaksi kemudian ditutup dengan cover glass dan didiamkan selama 20 menit. Cover glass kemudian diangkat dari tabung reaksi dan diletakkan pada object glass. Object glass kemudian diberi label nomor sampel dan tanggal pengambilan sampel (Ahmadi et al., 2017). Replikasi pengamatan TDR dilakukan sebanyak 3x. Preparat diperiksa menggunakan mikroskop cahaya dan diidentifikasi berdasarkan hasil penelitian (Ponggalunggu, Pijoh and Wahongan, 2015); Rahmadatu dan Sulistyaningsih, 2019) Hasil identifikasi dicatat untuk dihitung 
kepadatannya per gram debu. Rumus untuk menghitung kepadatan TDR adalah sebagai berikut:

Kepadatan TDR $=$

$\frac{\text { berat debu keseluruhan ( } \mathrm{g})}{0,1 \text { gram }} \times$ jumlah TDR dalam $0,1 \mathrm{gr}$ debu

( Rahmadatu, dan Sulistyaningsih, 2019)

\section{HASIL}

Hasil pemeriksaan TDR pada kamar tidur di Pondok Pesantren X di Kota Bekasi dapat dilihat pada gambar di bawah ini:

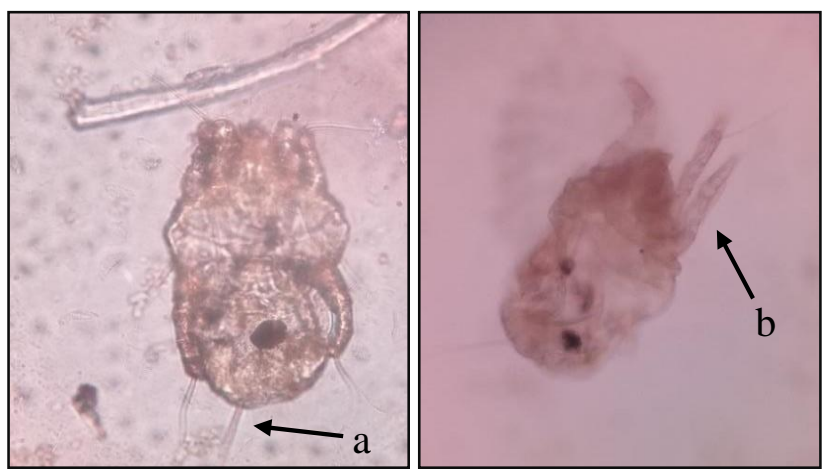

Gambar 1. Tungau Debu Rumah (Dermatophagoides sp) perbesaran 400x, (a) setae, (b) kaki.

TDR dengan genus Dermatophagoides sp. Ciri-ciri morfologi tubuh Dermatophagoides sp. yang ditemukan berwarna krem atau kecoklatan. Adapun bagian tubuh Dermatophagoides $s p$. yang terlihat saat identifikasi dengan mikroskop perbesaran 400x adalah setae (rambut) dan kaki, sedangkan bagian bursa capulatrix, anal sucker, epiginium dan chelicerae tidak terlihat dengan jelas. Adapun Hasil kepadatan TDR yang diambil dari sampel debu di 13 kamar tidur Pondok Pesantren X kota Bekasi dapat dilihat pada tabel di bawah ini :

Tabel. Hasil Kepadatan Tungau Debu Rumah Dermathopagoides sp pada Sampel Debu diPondok Pesantren Bekasi

\begin{tabular}{cccc}
\hline Sampel & $\begin{array}{c}\text { Berat debu total } \\
\text { (gr) }\end{array}$ & $\begin{array}{c}\text { Rata-rata } \\
\text { jumlah TDR }\end{array}$ & $\begin{array}{c}\text { Rata-rata kepadatan } \\
\text { tdr/gr debu }\end{array}$ \\
\hline 1 & 0,69 & 2 & 13,80 \\
2 & 0,65 & 1 & 6,5 \\
3 & 0,53 & 1,7 & 8,83 \\
4 & 0,61 & 1,3 & 8,13 \\
5 & 0,48 & 2 & 9,60 \\
6 & 0,57 & 1,3 & 7,60 \\
7 & 0,45 & 1 & 4,50 \\
8 & 0,60 & 1,3 & 8,00 \\
9 & 0,52 & 1 & 5,20 \\
10 & 0,46 & 1 & 4,60 \\
11 & 0,56 & 1 & 5,60 \\
12 & 0,68 & 1,67 & 11,33 \\
13 & 0,52 & 1,67 & 6,93 \\
\hline
\end{tabular}

Tabel di atas memperlihatkan bahwa 13 sampel debu yang diambil dari kamar tidur semuanya menunjukkan hasil positif TDR. Jumlah kepadatan TDR tertinggi terdapat pada sampel debu tempat tidur no 1 dengan rerata kepadatan sebesar 13,80 tungau/gram debu, sedangkan jumlah kepadatan TDR terendah terdapatpada sampel debu tempat tidur no 7 dengan rerata kepadatan sebesar 4,50 tungau/gram debu. 


\section{PEMBAHASAN}

Hasil identifikasi TDR yang ditemukan pada 13 sampel debu tempat tidur di pondok pesantren X kota bekasi menunjukkan adanya genus Dermatophagoides sp. Hasil identifikasi diketahui dari pengamatan menggunakan mikroskop perbesaran $400 \mathrm{x}$ yang menunjukkan ciri-ciri morfologi berupa tubuh berwarna krem atau kecoklatan, memiliki setae (rambut), kaki, tidak memiliki sayap dan antena. Hasil identifikasi pada penelitian ini sesuai dengan penelitian Subahar et al (2019) mengenai keberadaan TDR di Pamulang dan Jakarta yang melaporkan bahwa morfologi Dermatophagoides sp. berupa kulit berwarna krem, memiliki empat pasang kaki dan cakar, tubuh ditutupi oleh setae, tidak terdapat sayap dan antena, memiliki chelicerae dan memiliki bursa capulatrix. Terkait dengan hasil identifikasi TDR, pada penelitian ini tidak terlihat dengan jelas adanya chelicerae dan bursa capulatrix. Selain itu, morfologi tubuh TDR secara keseluruhan tidak bisa terlihat dengan jelas. Hal ini disebabkan preparat TDR yang diamati dengan mikroskop tertutup oleh debu yang diambil dari kamar tidur.

Adapun hasil kepadatan TDR genus Dermatophagoides pada sampel debu tempat tidur pada penelitian ini paling tinggi sebesar 13,80 tungau/gram debu sedangkan paling rendah sebesar 4,50 tungau/gram debu. Pemilihan sampel debu pada tempat tidur didasarkan hasil penelitian Arrahmi et al (2019) mengenai kepadatan TDR pada rumah warga Kelurahan Jati Kecamatan Padang Timur Kota Padang menunjukkan hasil bahwa kepadatan TDR pada tempat tidur sebesar 15,1 tungau/gram debu sedangkan karpet sebesar 12,02 tungau/gram debu. Hasil tersebut memperlihatan bahwa kepadatan TDR pada tempat tidur lebih tinggi dibandingkan karpet.

Lesmana et al (2019) dalam penelitiannya mengenai identifikasi TDR pada pasien Dermatitis atopik di pekanbaru melaporkan bahwa meskipun TDR hampir dijumpai pada semua lokasi tempat tinggal namun TDR lebih banyak ditemukan di kamar tidur dibandingkan ruang tamu. Hal ini dapat disebabkan kamar tidur merupakan lokasi paling banyak ditemukannya epitel kulit manusia yang merupakan sumber makanan bagi TDR. Selain itu, kamar tidur memiliki kecenderungan untuk tidak dibersihkan. Adanya sumber makanan dan menjadikan TDR dapat melangsungkan siklus hidupnya dengan baik.

Alasan lain mengenai kepadatan TDR lebih tinggi pada tempat tidur dikemukakan Rahmadatu, Sulistyaningsih, dan Agustina, (2019) bahwa rata-rata manusia menghabiskan waktunya di tempat tidur sekitar 6-8 jam dengan jumlah rata-rata epitel kulit yang dihasilkan sebagai sumber makanan TDR sebanyak 0,5-1 gram. Selain itu, tempat tidur memiliki tingkat kelembaban yang cukup tinggi sehingga mendukung kemampuan reproduksi dan pernapasan dari TDR. Hasil penelitian ini memiliki keterbatasan sehingga penulis menyarankan :

1. Identifikasi TDR pada penelitian ini hanya sampai tingkat genus, sehingga perlu dilakukan identifikasi pada tingkat spesies

2. Data penelitian ini masih terbatas pada kepadatan TDR, sehingga perlu ditindaklanjuti dengan menambahkan data karakteristik responden, perilaku higiene responden, distribusi penyebaran TDR berdasarkan lokasi sampel

3. Penelitian ini masih terbatas melihat gambaran populasi TDR, sehingga perlu diperluas dengan melihat gambaran responden yang mengalami gejala asma dan dihubungkan dengan kepadatan TDR

\section{KESIMPULAN}

Hasil identifikasi TDR pada sampel debu di kamar tidur pondok pesantren $\mathrm{X}$ di kota Bekasi hanya ditemukan genus Dermatophagoides dengan kepadatan rerata tertinggi sebesar 13,80 tungau/gram debu.

\section{REFERENSI}

Denaneer Rahmadatu, Erma Sulistyaningsih, Dini Agustina (2019) 'Hubungan kepadatan dermatophagoides spp. dengan frekuensi serangan asma pada penderita asma di rs paru Jember', Jurnal Kedokteran SyiahKuala ISSN: 1412-1026 Volume 19, Number 2, Agustus 2019 E-ISSN: 25500112 Pages: 64-71, 2(9), pp. 64-71. doi: https://doi.org/10.24815/jks.v19i2.18058.

Arrahmi, F., Irawati, N. and Rita, R. S. (2019) 'Jurnal Dampak Gambaran Kepadatan Tungau Debu Rumah Spesies Dermatophagoides pteronyssinus dan Dermatophagoides farinae di Kelurahan Jati Kecamatan Padang Timur Kota Padang', Jurnal Dampak, 01, pp. 15-19.

Kawulur, Y. C. W., Tuda, J. S. B. and Wahongan, G. J. P. (2013) 'Jenis Dan Kepadatan Tungau Debu Rumah Yang Ditemukan Di Kelurahan Teling Bawah Kecamatan Wenang Kota Manado', Jurnal eBiomedik, 1(3), pp. 1081-1084. doi: 10.35790/ebm.1.3.2013.3263. 
Lesmana, S. D., Putra, D. P. and Widiawaty, A. (2019) 'Identifikasi Tungau Debu Rumah di Tempat Tinggal Pasien Dermatitis Atopik RSUD Petala Bumi Pekanbaru', Jurnal Ilmu Kedokteran, 12(2), p. 89. doi: $10.26891 /$ jik.v12i2.2018.89-94.

Mondal, P. et al. (2019) 'Evaluation of Sensitivity Toward Storage Mites and House Dust Mites among Nasobronchial Allergic Patients of Kolkata, India', Journal of Medical Entomology, 56(2), pp. 347352. doi: 10.1093/jme/tjy206.

Nova, D. F., Rusjdi, S. R. and Fitri, F. (2018) 'Perbedaan Paparan Tungau Debu Rumah dengan Status Rhinitis Alergi Berdasarkan Kriteria ISAAC pada Anak di Dua Panti Asuhan Kecamatan Koto Tangah', Jurnal Kesehatan Andalas, 7(2), p. 253. doi: 10.25077/jka.v7i2.810.

Ponggalunggu, W. F., Pijoh, V. D. and Wahongan, G. J. P. (2015) 'Jenis Dan Kepadatan Tungau Debu Rumah Pada Beberapa Habitat Di Rumah Penderita Penyakit Alergi', Jurnal e-Biomedik, 3(1). doi: 10.35790/ebm.3.1.2015.6734.

Rahmadatu, D., Sulistyaningsih, E. and Agustina, D. (2019) 'Hubungan Kepadatan Dermatophagoides spp. dengan frekuensi serangan asma pada penderita asma di RS Paru Jember', Jurnal Kedokteran Syiah Kuala, 19(2).

Setyabudi, I. D. and Song, C. (2020) 'Gambaran kepadatan tungau debu pada ruangan-ruangan Sekolah X Jakarta periode April - Juni 2018', Tarumanagara Medical Journal, 2(2), pp. 279-288.

Soleimani-Ahmadi, M. et al. (2017) 'Species identification and prevalence of house dust mites as respiratory allergen in kindergartens of the bandar abbas city', Iranian Journal of Allergy, Asthma and Immunology, 16(2), pp. 133-139.

Subahar, R. et al. (2019) 'Pengaruh Suhu dan Kelembaban Udara terhadap Keberadaan Tungau Debu Rumah di Pamulang dan Jakarta', Jurnal Ilmiah WIDYA Kesehatan dan Lingkungan, 1(2), pp. 142147.

Widiastawan, K. A. W., Wahongan, G. J. P. and Bernadus, J. B. B. (2015) 'Jenis Dan Kepadatan Tungau Debu Rumah Di Kelurahan Malalayang Dua Kecamatan Malalayang Kota Manado', Jurnal eBiomedik, 3(3), pp. 733-737. doi: 10.35790/ebm.3.3.2015.9367.

Yu, J. M. et al. (2015) 'Diversity of House Dust Mite Species in Xishuangbanna Dai, a Tropical Rainforest Region in Southwest China', BioMed Research International, 2015. doi: 10.1155/2015/421716. 